\title{
The influence the horizontal structure of the forest on the passing the L1 range of navigation satellites signals
}

\author{
Anatoly Sorokin ${ }^{1}$, Alexander Borisov $^{2}$, Mikhail Reushev ${ }^{1}$, Victor Ivanov $^{2}$, Dmitriy \\ Kharlamov $^{1}$ \\ ${ }^{1}$ Federal Research Center KSC SB RAS, Krasnoyarsk, Russian Federation \\ ${ }^{2}$ Institute of Forest named after V.N. Sukacheva FRC KSC SB RAS, Krasnoyarsk, Russian \\ Federation
}

\begin{abstract}
Experimental data on the passing of signals from navigation satellites of the L1 range through forest plantations with an anisotropic horizontal tree arrangement structure are presented. A feature of the studied environment is an irregular distance between trees in rows and a constant distance between rows. Signals were recorded by an antenna located inside the forest at heights of 0.5 and 10 meters. Based on the results of processing the amplitude-time dependences of the recorded signal by means of fast Fourier transform, qualitative differences were revealed depending on the orientation of the probe signal path in the forest stand.
\end{abstract}

\section{Introduction}

The formation of forest stands in forestry practice is carried out by planting seedlings and is an important tool for growing forest of highly productivity. Seedlings are usually planted in rows, but the arrangement of growing trees in one row becomes irregular over time. Forest care measures can weaken competition, increase the available resource for trees of higher quality and shorten the growing time. Such activities are carried out taking into account the intended purpose of forests $[1-3]$.

The competition between all the trees of the stand even-aged stands of natural origin increases almost simultaneously by the time the crowns overlap. This leads to a massive fall of trees and even the surviving trees are in a significantly weakened state. In a planted stands, due to rows structure process of competition is separated in time and occurs in two stages. At the first stage, crowns are closing in the rows and competition for lighting is intensifying. This leads to the differentiation of trees by the diameter and size of the crowns and some trees falling off. The second stage occurs at the age of closing the crowns between the rows. Therefore, the process of tree fall in natural forests and forest plantations proceeds in different ways as a result of the difference in the horizontal structure of stands. It is necessary to control the density of the stand and the amount of wood stock, regardless of the horizontal structure, and timely cut down weakened and stunted trees. The particular importance in the cultivation of forests is getting operative information about the horizontal 
structure of the stand and the assessment of the ratio of biomass fractions of crowns and tree trunks. These data are available using instrumental methods for estimation the attenuation of satellite navigation signals during passing through the forest. The characteristics of the trunk wood and tree crowns affect the parameters of the NS signals during the passage of signals through the forest canopy with an azimuth along or across the rows.

This paper presents the results of monitoring the anisotropy of the horizontal structure of pine forest plantations at the age of 72 years using signals from navigation satellites (NS) of the L1 range.

\section{Object of study}

The experimental test site is the pine plantations of the 1st quality class, located on the territory of urban forests near Akademgorodok. The plantations are 72 years old. The size of the plot is $480 \times 90$ meters. The main taxation characteristics of the pine stand are as follows; stand density $1425 \mathrm{pcs} / \mathrm{ha}$; average tree height (hav) - $25 \mathrm{~m}$; the average diameter at breast height $-24.2 \mathrm{~cm}$; stock of stem wood $-743 \mathrm{~m}^{3} / \mathrm{ha}$; the sum of the cross-sections of the trunks $-65.5 \mathrm{~m}^{2} /$ ha; stand fullness -1.47 . Pines were planted in rows oriented along an azimuth of $72^{\circ}$ with a row spacing of 3 meters. The distance between trees in rows varies from 1 to 3 meters with an average distance between trees in a row of $1.5 \mathrm{~m}$. The stand density in the test plot significantly exceeds this parameter for a normal stand at this age -757 pcs / ha [4]. Competition arises between trees for available resources, which leads to a weakening of the stand as a whole and a smaller average diameter of trunks with poorly developed crowns. The bulk of trees (more than 80\%) in the classification according to the degree of domination and oppression belongs to the III and IV classes of Kraft [5].

The top view of the site is shown in Figure 1a. The internal structure of the stand with an azimuth along or across the rows is shown in Figures $1 \mathrm{~b}$ and 1c.
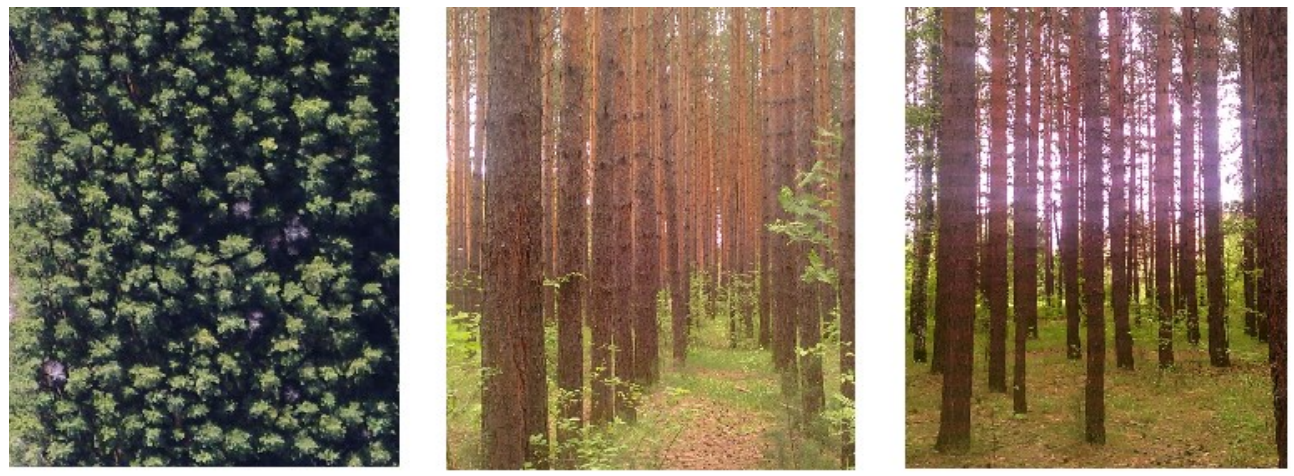

Fig 1. View of the fragment of the test site from above - a), ground image of the stand, along the rows $-\mathrm{b}$ ), perpendicular to the rows $-\mathrm{c}$ ).

The horizontal structure of the stand has a pronounced anisotropy. The spacing between rows is twice the average spacing between trees in a row. In the process of growth, a layered structure of the distribution of trees in the form of rows appears.

In the vertical direction, the stand also has a layered structure. An estimate of the ratio of the effective average density of biomass in the layers of pine crowns and trunks gives a value of $1 / 16$ [6]. The vertical complete orientation ordering of the trunks and partial branches of the crowns is realized in the stand. There are significant differences in the 
electrophysical properties of crown layers and tree trunks - biomass density and anisotropy of the effective dielectric constant of the stand.

\section{Passing of NS signals through the pine stand}

The attenuation of NS signals passing through a forest area depends on the size of the trunks and the density of the trees- stand. The stand fullness of the test site exceeds by $47 \%$ that for a "normal trees-stand" [4].

In the vertical direction, the tree stand has a layered structure. The top layer, formed by tree crowns, is at a height of 15 to 20 meters. The average crown height is $5.4 \mathrm{~m}$, the trunk layer $19.6 \mathrm{~m}$. Estimation of the ratio of the average biomass density of the crown and trunk layers gives a value of 1/16 [4]. Vertical orientational ordering of trunks and partial ordering of crown branches are realized in the tree stand. There are differences in the electrical properties of the crowns and trunks of the trees-stand: the density of biomass, the vertical extent of the magnitude and the anisotropy of the dielectric constant.

Measurements of the characteristics of signals from the NS systems GLONASS, GPS, Galileo in the process of propagation in the trees-stand were carried out using a specialized four-channel receiver. The receiving antenna recording navigation signals with right-hand circular polarization was placed at heights of $h_{1}=10 \mathrm{~m}$ and $h_{2}=0.5 \mathrm{~m}$ from the earth's surface. The trajectories and the length of the paths of the NS signals in the stand were determined from the data of the location of satellites, the length of the layers of crowns and trunks, and the heights of the antenna above the soil.

The measurement scheme is shown in Fig. 2.

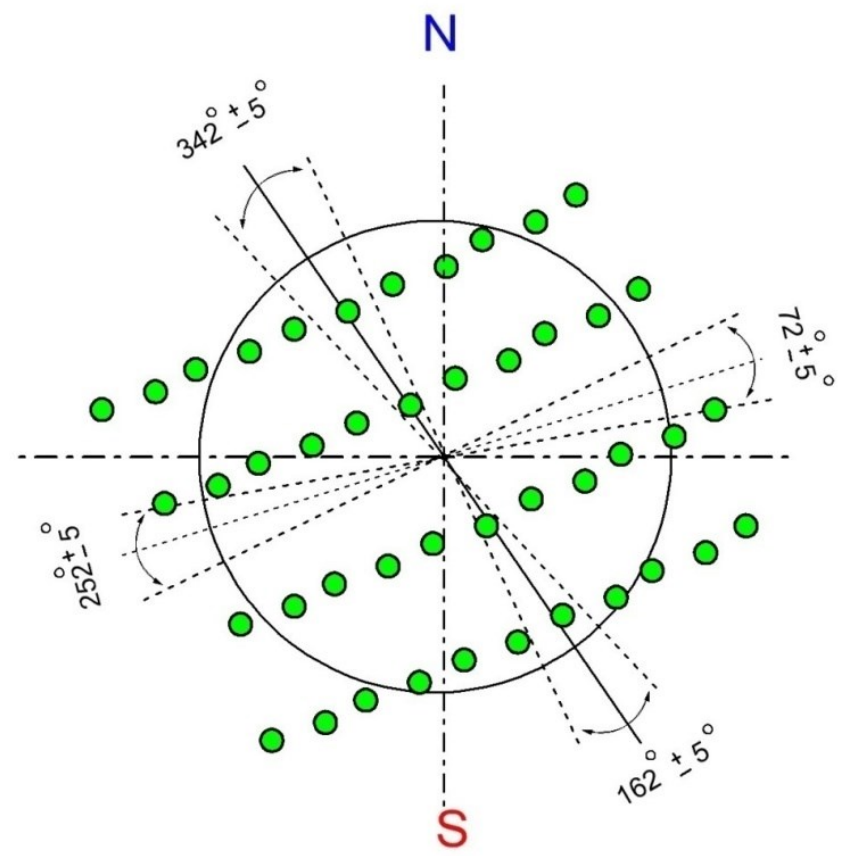

Fig 2. Scheme of measurements of navigation signals on the test site.

The antenna pattern was oriented vertically. The receiver recorded the values of the magnitude proportional to the power of the transmitted signal, averaged over 1 second in 
the form of amplitude-time dependences (ATD). The set of signals from the NS recorded by the receiver made it possible to determine the coordinates of the sounding volume of the stand and the coefficients of linear attenuation with a coordinate reference [7].

\section{Results and discussion}

Examples of measured individual ATD at antenna heights $h_{1}$ and $h_{2}$ are shown in Figures 3 and 4 in the form of normalized (per unit) functions $S(t)$.

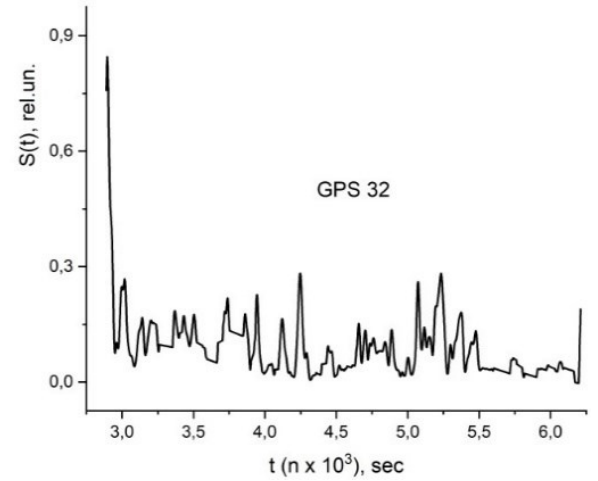

a.

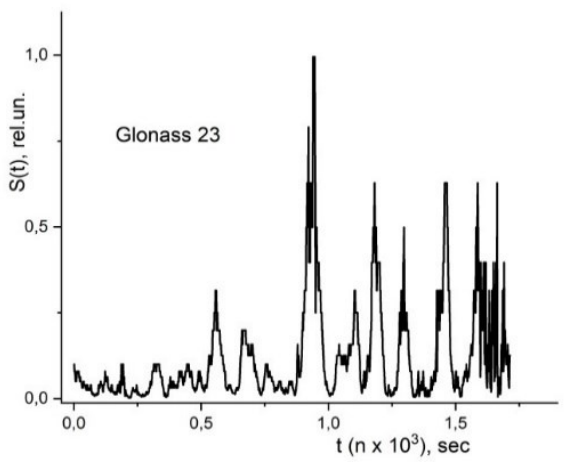

b.

Fig 3.ATD, antenna height $\mathrm{h}_{1}=10 \mathrm{~m}$ :(a.) NS GPS - 32 (azimuth $\approx 342^{\circ}$, elevation $\approx 30^{\circ}$ ); (b.) NS GLONASS -23 (azimuth $\approx 250^{\circ}$, elevation $\approx 30^{\circ}$ ).

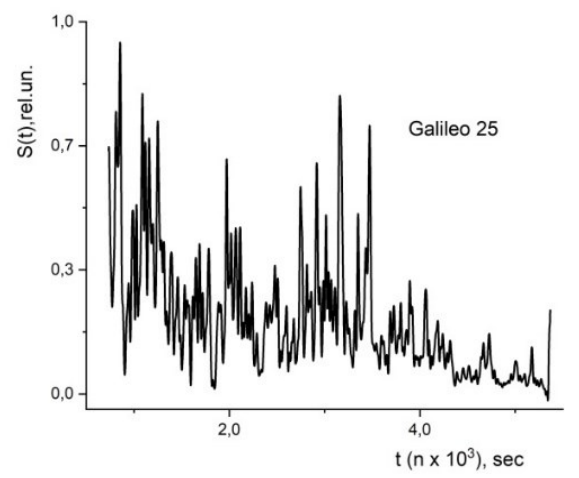

a.

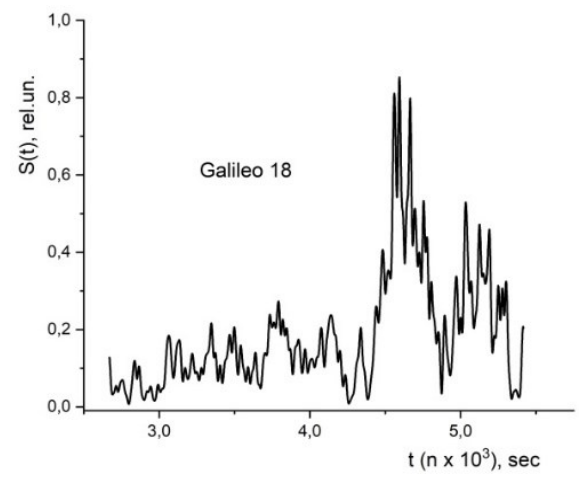

b.

Fig 4. ATD, antenna height $\mathrm{h}_{2}=0.5 \mathrm{~m}:\left(\mathrm{a}\right.$.) NS Galileo- 25 (azimuth $\approx 160^{\circ}$, elevation $\approx 30^{\circ}$ ); (b.) NS Galileo -18 (azimuth $\approx 260^{\circ}$, elevation $\approx 30^{\circ}$ ).

As can be seen from Figures 3 and 4, the form of the $\mathrm{S}(\mathrm{t})$ dependences for the NS at a height close to the ground surface $\left(\mathrm{h}_{2}=0.5 \mathrm{~m}\right)$ differs from the form of the $\mathrm{S}(\mathrm{t})$ dependences obtained during measurements at a height near the lower boundary of the tree crown layer $\left(\mathrm{h}_{1}=10 \mathrm{~m}\right)$ for directions of signal propagation along $(=)$ and across $(+)$ tree rows.

Analysis of $\mathrm{S}(\mathrm{t})$ with the use of fast Fourier transform (FFT) determined qualitative regularities in the registration of NS-signals in the orthogonal directions $(=)$ and $(+)$ of the trees-stand structure. Figures 5 and 6 show the results of processing $S(t)$ in the form of dependences $S(v)$. 


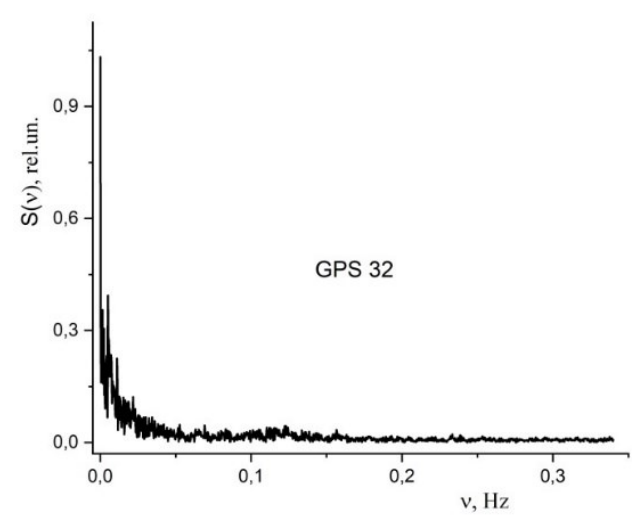

a.

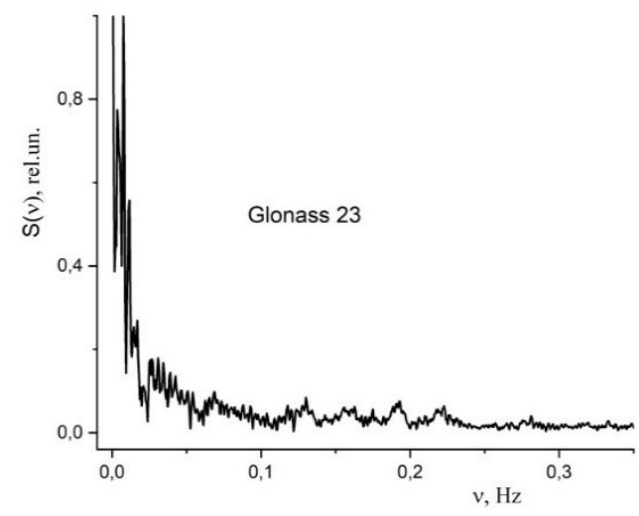

b.

Fig 5. FFT, antenna height $\mathrm{h}_{1}=10 \mathrm{~m}$ :(a.) NS GPS - 32 (azimuth $\approx 342^{\circ}$, elevation $\approx 30^{\circ}$ ); (b.) NS GLONASS - 23 (azimuth $\approx 250^{\circ}$, elevation $\approx 30^{\circ}$ ).

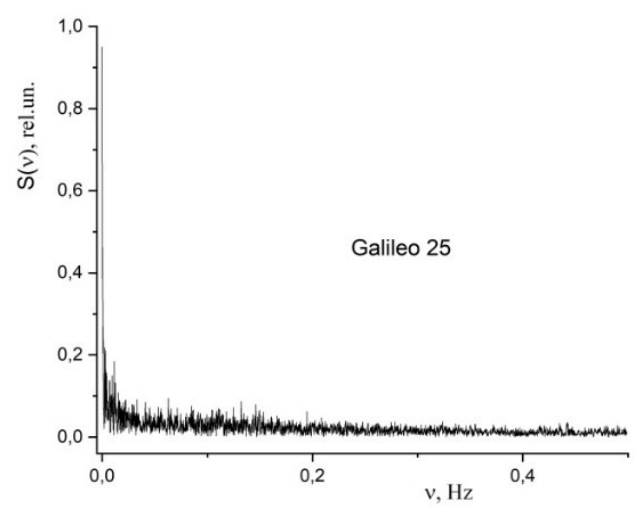

a.

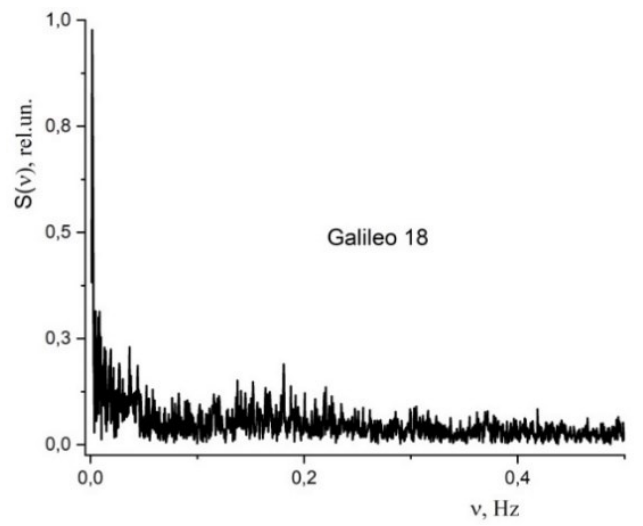

b.

Fig 6. FFT, antenna height $\mathrm{h}_{2}=0.5 \mathrm{~m}$ :(a.) NS Galileo -25 (azimuth $\approx 160^{\circ}$, elevation $\approx 30^{\circ}$ ); (b.) NS Galileo -18 (azimuth $\approx 260^{\circ}$, elevation $\approx 30^{\circ}$ ).

It can be seen from Figures 5 and 6 that the Fourier spectra of NS have differences when they propagate in a forest along and across rows of trees. Similar differences were observed earlier in measurements using GNSS - reflectometry of various surfaces of the earth's covers [8]. Subsequent analysis made it possible to interpret the results obtained in the form of a function $\mathrm{S}(v)$ :

$$
S(v)=S_{0} v^{-\alpha}
$$

Here $\mathrm{S}_{0}$ is the maximum amplitude of the Fourier harmonics, the amplitude of the signal $S(v), \alpha$ is the exponent depending on the structure of the trees- stand (crown, trunks) of the studied taxation area, $v-$ is the frequency in $\mathrm{Hz}$.

In the examples under consideration (Figures 5 and 6), the coefficients of the functional dependence $S(v)$ are given in Table 1.

Table 1. Coefficients of dependence S $(v)$.

\begin{tabular}{|c|c|c|c|c|c|}
\hline № & Наименование НC & $S_{0}$ & $\alpha$ & $h, \mathrm{M}$ & НСД \\
\hline 1 & GPS -32 & 0.78 & 0.77 & 10 & $(+)$ \\
\hline
\end{tabular}




\begin{tabular}{|c|c|c|c|c|c|}
\hline 2 & GLONASS -23 & 0.50 & 0.81 & 10 & $(=)$ \\
\hline 3 & Galileo -25 & 1.86 & 0.47 & 0.5 & $(+)$ \\
\hline 4 & Galileo -18 & 71.09 & 0.43 & 0.5 & $(=)$ \\
\hline
\end{tabular}

As can be seen from Table 1, the attenuation coefficients of the function $\mathrm{S}(v)$ when registering signals from the NS in the crown layer, $\left(\mathrm{h}_{1}=10 \mathrm{~m}\right)$ in relation to the signals recorded in the trunk layer $\left(\mathrm{h}_{2}=0.5 \mathrm{~m}\right)$.

Similar differences in the coefficients $\alpha$ were also observed when the NS was recorded by the receivers at heights of $h_{1}=10 \mathrm{~m}$ and $h_{2}=0.5 \mathrm{~m}$ from other satellites. The results of the research allow us to conclude that the observed qualitative differences in ATD followed by processing using a fast Fourier transform can determine the parameters for a quantitative assessment of the biometric characteristics of the trees-stand.

\section{Conclusions}

Measurements of the amplitude-time dependences of the signals of navigation satellites in the layers of crowns and trunks of pine plantations with an anisotropic horizontal structure of tree arrangement in the form of parallel rows have been carried out.

In the array of experimental data, a sample of trajectories of the direction of signals passing along and across the rows of trees was carried out. The differences in the amplitude-time dependences of such signals are revealed.

The processing of the amplitude-time dependences of the signals using the fast Fourier transform has been carried out. The differences in the Fourier spectra were revealed depending on the orientation of the path of the sounding signal in the forest stand.

A quantitative interpretation of the Fourier spectra in the form of an empirical exponential function is proposed.

\section{References}

1. Borisov, A.N., Ivanov, V.V. and Petrenko, A.E., 2019. Formation of the spatial structure of pine stands during thinning. Forestry, (1), pp. 7-18.

2. Nagimov, Z.Ya., 2000. Regularities of growth and formation of aboveground phytomass of pine stands (Doctoral dissertation, Ural State Forestry University).

3. Rogozin, M.V. and Razin, GS, 2015. Development of forest stands. Models, laws, hypotheses.

4. Shvidenko, A.Z., Shchepashchenko, D.G., Nilsson, S. and Bului, Yu.I., 2008. Tables and models of growth and productivity of planting of the main ec-forming rocks of northern Eurasia.

5. Eitingen G.R. Forestry. Moscow .: Selkhozgiz. 1949.246 s.

6. Stakanov, VD, 1990. Distribution of organic matter in different parts of Scots pine trees. Forestry, (4), p. 25.

7. Pat. 2682718 of the Russian Federation. IPC G01S 19/03 (2010.01) Method for determining the linear attenuation coefficients of navigation spacecraft signals in a woodland with coordinate reference // Makarov D.S., Savin I.V., Sorokin A.V., Fomin S.V. Kharlamov D.V. No. 2018119448; declared 05/25/2018; publ. 03/21/2019, Bul. No. 9.8 p.

8. Kuzmin, E.V. and Sorokin, AV, 2021. Fourier spectra of amplitude variations of the superposition of signals from navigation satellites near surfaces with different properties. Letters to the Journal of Technical Physics, 47 (18), pp. 26-28. 